\title{
First Report of Predominant MEFV Mutations in a Persian Children Population with Familial Mediterranean Fever: R202Q, M694V/I
}

\section{Shirin Sayyahfar ${ }^{1}$, Reza Shiari ${ }^{2}$, Fahimeh Shahmiri ${ }^{1}$, Farzaneh Vali ${ }^{3}$, Babak Behnam ${ }^{3,4 *}$}

${ }^{1}$ Department of Pediatrics, Ali Asghar Children Hospital, Iran University of Medical Sciences (IUMS), Tehran, Iran

${ }^{2}$ Department of Pediatrics, Mofid Children's Hospital, Shahid Beheshti University of Medical Sciences, Tehran, Iran

${ }^{3}$ Departments of Medical Genetics and Molecular Biology, Iran University of Medical Sciences (IUMS), Tehran, Iran

${ }^{4}$ NIH Undiagnosed Diseases Program, Common Fund, Office of the Clinical Director, National Human Genome Research Institute (NHGRI), National Institute of Health (NIH), Bethesda, Maryland, USA

${ }^{*}$ Corresponding author: Babak Behnam, MD, PhD, NIH Undiagnosed Diseases Program, National Human Genome Research Institute (NHGRI), National Institute of Health (NIH), Bethesda, MD 20892, Maryland, USA, Tel- 301-594-5182; E-mail: b_behnam@yahoo.com

Received January 15, 2018;Accepted January 20, 2018; Published January 23, 2018

\section{Retraction Note:}

The article entitled "First Report of Predominant MEFV Mutations in a Persian Children Population with Familial Mediterranean Fever: R202Q, M694V/I" has been accepted for publication in the journal Hereditary Genetics: Current Research considering the statements provided in the article as personal opinion of the author which was found not having any conflict or biasness towards anything. As the article was a perspective one, information provided by the author was considered as an opinion to be expressed through publication.

Publisher took decision to make the article online solely based on the reviewer's suggestion which considered the article not but a personal opinion of the author. However, it is found that the author has some personal concerns and issues, therefore, being retracted from the journal. 